\title{
Lymphocyte-monocyte ratio at day 14 of first cisplatin-doxorubicin chemotherapy is associat- ed with treatment outcome of pediatric pati- ents with localized osteosarcoma
}

\author{
Jun Ah Lee, MD, PhD, Hea Lin Oh, MD, Dong Ho Kim, MD, Jung Sub Lim, MD, PhD \\ Department of Pediatrics, Korea Cancer Center Hospital, Seoul, Korea
}

Purpose: We aimed to determine the prognostic significance of lymphocyte counts and the lymphocytemonocyte ratio (LMR) in pediatric patients with osteosarcoma.

Methods: We retrospectively reviewed the medical records of 27 pediatric patients with localized extremity osteosarcoma, treated at the Korea Cancer Center Hospital between May 2002 and March 2016. Leukocyte counts and LMR before treatment and on day 14 (LMR14) of the first cisplatin-doxorubicin chemotherapy round were evaluated. Patients were dichotomized according to the median value of these parameters, and survival rates were compared.

Results: The median age of the 27 patients was 9.9 years (range, 3.2-14.1 years) and tumor sites were: distal femur $(n=14)$, proximal humerus $(n=7)$, proximal tibia $(n=2)$, proximal fibula $(n=2)$, and elsewhere $(n=2)$. Patients were followed up on for a median of 76.4 months (range, 4.5-174.7 months), and 5-year overall (OS) and event-free survival (EFS) rates were $66.0 \% \pm 9.8 \%$ and $60.9 \% \pm 9.7 \%$, respectively. Patients with a higher pretreatment lymphocyte count $(\geq 2,320 / \mu \mathrm{L})$ had better OS $(90.9 \%$ vs. $46.2 \%$, $P=0.04$ ) and EFS (83.9\% vs. 38.5\%, $P=0.02$ ). However, the day 14 lymphocyte count was not associated with survival. While no survival difference was observed between patients grouped according to pretreatment LMR (median value, 6.3), patients with a higher LMR14 $(\geq 5)$ fared better than those with lower LMR14 (5-year 0S: $83.3 \%$ vs. $46.3 \%, P=0.04$ ).

Conclusion: Pretreatment lymphocyte count and LMR during chemotherapy had prognostic significance in pediatric osteosarcoma patients. Further studies involving larger cohorts are necessary to validate our findings.

Key words: Osteosarcoma, Lymphocyte, Monocyte, Ratio, Treatment outcome

\section{Introduction}

Osteosarcoma is the most common primary bone tumor in children and adolescents, with traditional therapeutic protocols comprising chemotherapy and surgical resection. ${ }^{1 .}$ Previous studies have suggested several clinical features related to prognosis, including age, tumor location and size, histologic response to chemotherapy, and serum alkaline phosphatase level. ${ }^{2)}$ Histologic response to preoperative chemotherapy is the most agreed-upon prognostic indicator; however, it can only be obtained after surgery. ${ }^{2)}$ Thus, a new clinical prognostic indicator available early in therapy is necessary.

Leukocyte count in the peripheral blood of cancer patients has prognostic significance. Reported clinical data have shown that a low lymphocyte count was associated with advanced
Corresponding author: Jun Ah Lee, MD, PhD

Department of Pediatrics, Korea Cancer Center Hospital, 75 Nowon-ro, Nowon-gu, Seoul 01812, Korea

Tel: $+82-2-970-1248$

Fax: +82-2-970-1970

E-mail: junahlee@kcch.re.kr

https://orcid.org/0000-0003-3310-9566

Received: 3 May, 2018

Revised: 28 September, 2018

Accepted: 1 October, 2018
Copyright (C) 2019 by The Korean Pediatric Society

This is an open-access article distributed under the terms of the Creative Commons Attribution NonCommercial License (http://creativecommons.org/ licenses/by-n/4.0// which permits unrestricted noncommercial use, distribution, and reproduction in any medium, provided the original work is properly cited. 
stages and poor survival of cancer patients. ${ }^{3)}$ Recently it has been suggested that the lymphocyte-monocyte ratio (LMR) has prognostic significance in various cancers. ${ }^{4)}$ In patients with diffuse large Bcell and Hodgkin lymphoma, a low pretreatment LMR indicated a poor prognosis., ${ }^{5,6)}$ Additionally, in patients with nonhematologic malignancies, including breast, colorectal, lung, and nasopharyngeal carcinomas, a low pretreatment LMR represented an unfavorable prognosis. ${ }^{7-10)}$ In pediatric malignancies, limited data are available about the prognostic significance of lymphocyte counts or the LMR. Furthermore, previous studies varied in the time point of analysis (pretreatment or at the nadir of first chemotherapy) or leukocyte indices (LMR or lymphocyte count). It has been reported that the absolute lymphocyte count (ALC) at the end of induction chemotherapy is a prognostic factor in childhood acute lymphoblastic leukemia. ${ }^{11-13)}$ Preoperative LMR was a predictor of survival in patients with osteosarcoma. ${ }^{14)}$ Early lymphocyte recovery after first chemotherapy, defined at day 14 or 15, was associated with better outcomes in children with osteosarcoma and Ewing sarcoma. ${ }^{15-17)}$

In this retrospective study, we analyzed leukocyte counts and their ratios in the peripheral blood of pediatric patients with osteosarcoma and evaluated their association with treatment outcomes. Most previous studies analyzed the prognostic value of pretreatment lymphocyte counts and LMR. Day 14 of cytotoxic chemotherapy is usually considered as the nadir, and we hypothesized that the leukocyte count and its ratios at this time point might reflect the actual immune status against the tumor. Leukocyte counts and ratios at 2-time points (pretreatment and day 14) were assessed, and we found that day 14 LMR (LMR14), as well as pretreatment lymphocyte count, had prognostic significance in pediatric osteosarcoma patients.

Table 1. Clinical characteristics of the 27 patients with osteosarcoma

\begin{tabular}{|c|c|c|c|c|c|c|c|c|c|c|c|c|c|}
\hline \multirow[b]{2}{*}{ Case } & \multirow{2}{*}{$\begin{array}{c}\text { Age }(y r) / \\
\text { sex }\end{array}$} & \multirow[b]{2}{*}{ Location } & \multicolumn{4}{|c|}{ Pretreatment } & \multicolumn{4}{|c|}{ At day14 of cisplatin-doxorubicin } & \multirow[b]{2}{*}{ Events (mo) } & \multirow{2}{*}{$\begin{array}{l}\text { Follow-up } \\
\text { (mo) }\end{array}$} & \multirow{2}{*}{$\begin{array}{l}\text { Final } \\
\text { status }\end{array}$} \\
\hline & & & $\begin{array}{l}\text { ALC } \\
(/ \mu \mathrm{L})\end{array}$ & $\begin{array}{l}\text { ANC } \\
(/ \mu \mathrm{L})\end{array}$ & $\begin{array}{l}\mathrm{AMC} \\
(/ \mu \mathrm{L})\end{array}$ & LMR & $\begin{array}{c}\text { ALC14 } \\
(/ \mu \mathrm{L})\end{array}$ & $\begin{array}{c}\text { ANC14 } \\
(/ \mu \mathrm{L})\end{array}$ & $\begin{array}{c}\mathrm{AMC14} \\
(/ \mu \mathrm{L})\end{array}$ & LMR14 & & & \\
\hline 1 & $7.8 / \mathrm{M}$ & Fibula & 3,660 & 1,810 & 350 & 10.5 & 970 & 850 & 360 & 2.7 & - & 118.7 & CDF \\
\hline 2 & $10.2 / \mathrm{M}$ & Femur, distal & 1,960 & 2,910 & 280 & 7.0 & 1,420 & 580 & 70 & 20.3 & Lung meta (11.5) & 47.7 & DOD \\
\hline 3 & $9.7 / F$ & Femur, distal & 4,300 & 2,800 & 200 & 21.5 & 2,030 & 4610 & 820 & 2.5 & - & 110.2 & CDF \\
\hline 4 & 3.2/M & Humerus, proximal & 2,470 & 2,890 & 330 & 7.5 & 1,560 & 40 & 140 & 11.1 & - & 32.4 & CDF \\
\hline 5 & $9.1 / \mathrm{M}$ & Femur, distal & 1,790 & 5,660 & 430 & 4.2 & 1,750 & 2,060 & 260 & 6.7 & - & 72.8 & $\mathrm{CDF}$ \\
\hline 6 & $12.5 / \mathrm{M}$ & Humerus, proximal & 1,730 & 3,020 & 370 & 4.7 & 1,330 & 210 & 90 & 14.8 & Lung meta (6.9) & 174.7 & NED \\
\hline 7 & $5.0 / \mathrm{M}$ & Humerus, proximal & 1,980 & 6,020 & 340 & 5.8 & 2,010 & 600 & 400 & 5.0 & Lung meta (26.8) & 37.5 & DOD \\
\hline 8 & $8.8 / \mathrm{M}$ & Femur, distal & 1,850 & 3,590 & 470 & 3.9 & 1,500 & 250 & 90 & 16.7 & - & 123.4 & CDF \\
\hline 9 & $14.1 / \mathrm{M}$ & Femur, distal & 1,910 & 6,080 & 820 & 2.3 & 1,410 & 130 & 70 & 20.1 & - & 126.9 & CDF \\
\hline 10 & $4.8 / \mathrm{M}$ & Femur, distal & 4,590 & 7,040 & 910 & 5.0 & 2,340 & 140 & 340 & 6.9 & - & 11.0 & $\mathrm{CDF}$ \\
\hline 11 & $7.8 / F$ & Humerus, proximal & 2,520 & 3,610 & 270 & 9.3 & 2,600 & 2,540 & 890 & 2.9 & - & 88.3 & $\mathrm{CDF}$ \\
\hline 12 & $6.6 / F$ & Radius, distal & 3,330 & 3,520 & 430 & 7.7 & 880 & 70 & 200 & 4.4 & - & 122.2 & $\mathrm{CDF}$ \\
\hline 13 & $10.9 / F$ & Humerus, proximal & 2,010 & 5,680 & 320 & 6.3 & 650 & 240 & 260 & 2.5 & Lung meta (25.5) & 53.9 & DOD \\
\hline 14 & 11.6/M & Femur, distal & 1,770 & 5,770 & 420 & 4.2 & 830 & 1,470 & 280 & 3.0 & Local recur (16.1) & 56.1 & DOD \\
\hline 15 & $10.3 / F$ & Femur, distal & 2,320 & 4,870 & 220 & 10.5 & 2,550 & 1,210 & 770 & 3.3 & - & 34.7 & CDF \\
\hline 16 & $9.9 / \mathrm{M}$ & Femur, distal & 1,430 & 4,120 & 400 & 3.6 & 1,020 & 500 & 170 & 6.0 & - & 163.2 & CDF \\
\hline 17 & $9.0 / \mathrm{M}$ & Tibia, proximal & 2,600 & 4,780 & 300 & 8.7 & 2,610 & 260 & 320 & 8.2 & - & 112.0 & CDF \\
\hline 18 & $12.4 / \mathrm{M}$ & Humerus, proximal & 2,890 & 3,270 & 380 & 7.6 & 2,560 & 320 & 580 & 4.4 & lung meta (13.6) & 69.6 & DOD \\
\hline 19 & $9.0 / F$ & Femur, distal & 2,780 & 8,800 & 390 & 7.1 & 1,320 & 830 & 180 & 7.3 & - & 76.4 & $\mathrm{CDF}$ \\
\hline 20 & $11.1 / \mathrm{M}$ & Femur, distal & 2,100 & 4,650 & 420 & 5.0 & 1,740 & 1,810 & 70 & 24.9 & - & 163.3 & $\mathrm{CDF}$ \\
\hline 21 & $10.8 / F$ & Tibia, distal & 2,690 & 3,350 & 230 & 11.7 & 1,500 & 100 & 300 & 5.0 & - & 150.9 & CDF \\
\hline 22 & $12.2 / \mathrm{F}$ & Femur, distal & 1,660 & 11,020 & 550 & 3.0 & 1,030 & 4,360 & 400 & 2.6 & Lung meta (25.6) & 38.5 & DOD \\
\hline 23 & $10.4 / \mathrm{M}$ & Tibia, proximal & 2,422 & 4,920 & 1,011 & 2.4 & 2,230 & 100 & 100 & 22.3 & - & 110.0 & CDF \\
\hline 24 & $4.8 / \mathrm{M}$ & Fibula shaft & 1,560 & 1,510 & 250 & 6.2 & 1,540 & 5,470 & 850 & 1.8 & Infection (4.5) & 4.5 & TRM \\
\hline 25 & $11.8 / \mathrm{F}$ & Femur, distal & 3,050 & 3,480 & 320 & 9.5 & 1,610 & 2,710 & 530 & 3.0 & Lung meta (18.6) & 127.1 & DOD \\
\hline 26 & 13.7/M & Humerus, proximal & 1,470 & 2,670 & 530 & 2.8 & 930 & 370 & 420 & 2.2 & bone meta (9.1) & 11.3 & DOD \\
\hline 27 & $5.6 / \mathrm{M}$ & Femur, distal & 2,640 & 3,070 & 280 & 9.4 & 1,820 & 300 & 350 & 5.2 & - & 15.1 & $\mathrm{CDF}$ \\
\hline
\end{tabular}

ALC14, absolute lymphocyte count at day14; ANC14, absolute neutrophil count at day 14; AMC14, absolute monocyte count at day14; LMR, lymphocyte-monocyte ratio; meta, metastasis; CDF, continuously disease-free; DOD, died of disease; NED, no evidence of disease; TRM, treatment-related mortality. 


\section{Materials and methods}

\section{Patients and treatments}

We retrospectively identified 27 patients with osteosarcoma, treated at the Pediatric Department of Korea Cancer Center Hospital between May 2002 and March 2016. The study was approved by The Institutional Review Board of Korea Cancer Center Hospital (K-1710-002-014). Patients met the following criteria; (1) highgrade primary osteosarcoma; (2) no evidence of distant metastasis, i.e., localized disease; (3) no history of previous treatment, and (4) complete blood cell counts were tested before treatment and at the 14th day of first cisplatin-doxorubicin chemotherapy at our institution. Seven cases underwent surgery first and subsequently received 6 courses of combination chemotherapy. The remaining 20 patients received 2 courses of preoperative chemotherapy before undergoing definitive surgery. The standard chemotherapy was comprised of high-dose methotrexate ( $12 \mathrm{~g} / \mathrm{m}^{2}$ on days 1 and 8 ), cisplatin (100 mg/m on day 15), and doxorubicin $\left(60 \mathrm{mg} / \mathrm{m}^{2}\right.$ over 48 hours, on day 15). Postoperative chemotherapy was modified according to the histologic response; 8 patients with a good response $(\leq 10 \% \text { residual viable tumor })^{18)}$ received the same therapy as the preoperative chemotherapy, while 12 cases with poor response $\left(>10 \%\right.$ residual viable tumor) ${ }^{18)}$ were switched to an ifosfamidebleomycin-doxorubicin-cisplatin based protocol. The dosages of cisplatin and doxorubicin were the same as the preoperative doses, and ifosfamide $\left(14 \mathrm{~g} / \mathrm{m}^{2}\right)$ was infused continuously with bleomycin $\left(30 \mathrm{mg} / \mathrm{m}^{2}\right)$ for 7 days.

\section{Statistical analysis}

Patients were dichotomized according to the median values of absolute neutrophil count (ANC), ALC, absolute monocyte count (AMC), and LMR measured before treatment and at day 14 of first cisplatin-doxorubicin chemotherapy. Survival analysis was performed using the Kaplan-Meier method, and survival differences between the 2 groups were evaluated using the log-rank test. All calculations were performed using SPSS ver. 11.5 (SPSS Inc., Chicago, IL, USA), and $P$ values of $<0.05$ were considered significant.

\section{Results}

The median age of the 27 patients ( 9 female and 18 male) was 9.9 years (range, $3.2-14.1$ years). The tumor sites were distal femur $(n=14)$, proximal humerus $(n=7)$, proximal tibia $(n=2)$, proximal fibula $(n=2)$, and elsewhere $(n=2)$ (Table 1$)$. All patients received granulocyte colony stimulating factor during the neutropenic period after chemotherapy, starting from a neutrophil count $<500 / \mu \mathrm{L}$. In addition to selected 5-hydroxytryptamine receptor antagonists, dexamethasone was used as an antiemetic for all patients when they received cisplatin and doxorubicin. The median pretreatment
Table 2. Five-year survival according to clinical variables including leukocyte counts

\begin{tabular}{lrcccc}
\hline Variable & $\begin{array}{r}\text { No. of } \\
\text { cases }\end{array}$ & OS (\%) & $\begin{array}{c}P \\
\text { value }\end{array}$ & EFS (\%) & $\begin{array}{c}P \\
\text { value }\end{array}$ \\
\hline Sex & & & 0.80 & & 0.52 \\
$\quad$ Male & 18 & $61.3 \pm 12.5$ & & $58.4 \pm 12.2$ & \\
$\quad$ Female & 9 & $75.0 \pm 15.3$ & & $66.7 \pm 15.7$ & \\
Tumor location & & & 0.37 & & 0.17 \\
$\quad$ Distal femur & 14 & $72.7 \pm 13.4$ & & $67.1 \pm 13.5$ & \\
Proximal tibia & 2 & 100 & & 100 & \\
Proximal humerus & 7 & $34.3 \pm 19.5$ & & $28.6 \pm 17.1$ & \\
Elsewhere & 4 & $75.0 \pm 21.7$ & & $75.0 \pm 21.7$ & \\
Neoadjuvant chemotherapy & & & 0.50 & & 0.19 \\
Yes & 20 & $63.3 \pm 11.0$ & & $53.1 \pm 11.4$ & \\
$\quad$ No & 7 & $75.0 \pm 21.7$ & & $83.3 \pm 15.2$ & \\
Histologic response & & & 0.11 & & 0.09 \\
Good & 7 & $83.3 \pm 15.2$ & & $83.3 \pm 15.2$ & \\
Poor & 13 & $53.9 \pm 13.8$ & & $38.5 \pm 13.5$ &
\end{tabular}

Leukocyte counts

Pretreatment

ALC

$\begin{array}{llllll}\geq 2,320 / \mu \mathrm{L} & 14 & 90.0 \pm 9.5 & 0.04 & 83.9 \pm 10.5 & 0.02 \\ <2,320 / \mu \mathrm{L} & 13 & 46.2 \pm 13.8 & & 38.5 \pm 13.5 & \\ \text { AMC } & & & 0.57 & & 0.97 \\ \quad \geq 370 / \mu \mathrm{L} & 14 & 69.2 \pm 12.8 & & 62.3 \pm 13.4 & \\ <370 / \mu \mathrm{L} & 13 & 51.3 \pm 15.8 & & 59.2 \pm 14.1 & \\ \text { ANC } & & & 0.63 & & 0.20 \\ <3,610 / \mu \mathrm{L} & 13 & 65.8 \pm 14.1 & & 52.8 \pm 14.1 & \\ \geq 3,610 / \mu \mathrm{L} & 14 & 66.7 \pm 13.6 & & 69.2 \pm 12.8 & \\ \text { ALC/AMC } & & & 0.21 & & 0.16 \\ \geq 6.3 & 13 & 80.0 \pm 12.7 & & 76.2 \pm 12.1 & \\ <6.3 & 14 & 54.2 \pm 13.8 & & 47.1 \pm 13.8 & \end{array}$

At day 14 of CDDP-ADR

\begin{tabular}{|c|c|c|c|c|c|}
\hline ALC & & & 0.77 & & 0.44 \\
\hline$<1,540 / \mu \mathrm{L}$ & 13 & $61.5 \pm 13.5$ & & $53.9 \pm 13.8$ & \\
\hline$\geq 1,540 / \mu \mathrm{L}$ & 14 & $72.2 \pm 13.9$ & & $68.1 \pm 13.3$ & \\
\hline AMC & & & 0.25 & & 0.44 \\
\hline$<300 / \mu \mathrm{L}$ & 13 & $75.0 \pm 12.5$ & & $69.2 \pm 12.8$ & \\
\hline$\geq 300 / \mu \mathrm{L}$ & 14 & $56.8 \pm 14.9$ & & $52.0 \pm 14.4$ & \\
\hline ANC & & & 0.19 & & 0.27 \\
\hline$<580 / \mu \mathrm{L}$ & 13 & $81.5 \pm 11.9$ & & $75.2 \pm 12.6$ & \\
\hline$\geq 580 / \mu \mathrm{L}$ & 14 & $54.2 \pm 13.8$ & & $50.0 \pm 13.4$ & \\
\hline ALC/AMC (LMR14) & & & 0.04 & & 0.06 \\
\hline$<5.0$ & 12 & $46.3 \pm 15.0$ & & $41.7 \pm 14.2$ & \\
\hline$\geq 5.0$ & 15 & $83.3 \pm 10.8$ & & $78.3 \pm 11.2$ & \\
\hline
\end{tabular}

Values are presented as mean \pm standard deviation.

OS, overall survival; EFS, event-free survival; CDDP-ADR, cisplatin-adriamycin; ALC, absolute lymphocyte count; AMC, absolute monocyte count; ANC, absolute neutrophil count; LMR, lymphocyte-monocyte ratio.

*Analyzed in 20 patients who received preoperative chemotherapy. 
ANC, ALC, and AMC were 3,610/ $\mu \mathrm{L}$ (range, 1,510-11,020/ $\mu \mathrm{L}$ ), $2,320 / \mu \mathrm{L}$ (range, $1,430-4,590 / \mu \mathrm{L}$ ), and 370/ $\mu \mathrm{L}$ (range, 200-1,011/ $\mu \mathrm{L}$ ), respectively. The median pretreatment LMR was 6.3 (range, 2.3-21.5). At day 14 of first cisplatin-doxorubicin chemotherapy, median values of ANC, ALC, and AMC were 580/ $\mu \mathrm{L}$ (range, 40-

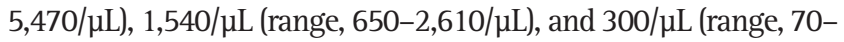
$890 / \mu \mathrm{L}$ ), respectively. In addition, the median LMR 14 was 5.0 (range, 1.8-24.9).

Patients were followed for a median of 76.4 months (range, 4.5174.7 months) and the 5-year overall (OS) and event-free survival (EFS) rates were $66.0 \% \pm 9.8 \%$ and $60.9 \% \pm 9.7 \%$, respectively. The 7 patients who underwent surgery first had similar OS and EFS to those who received surgery after chemotherapy. The 5-year OS and EFS were not different according to age and tumor location. For the 20 patients who received preoperative chemotherapy, histologic response tended to affect EFS $(P=0.09)$ (Table 2).

Patients were dichotomized according to the median values of pretreatment and day 14 ANC, ALC, AMC, and LMR, and survival rates were compared (Table 2). Patients with a higher pretreatment ALC had a better OS and EFS (Fig. 1A). However, survival was not different between the 2 patient groups according to their ALC values at day 14. We observed that a higher LMR14 was associated with a favorable outcome in osteosarcoma patients, while pretreatment LMR had no impact. Patients with an LMR $14 \geq 5.0$ had a better OS than those with a lower LMR14 $(<5.0)(P=0.04)$ (Fig. 1B). EFS also tended to be better in patients with an LMR14 $\geq 5.0$ than in those with an LMR14 <5.0 ( $P=0.06)$ (Fig. 1B).

\section{Discussion}

The role of the immune system has been demonstrated in many cancers. A low lymphocyte count has been observed in patients with advanced stages of cancer and is associated with poor survival. ${ }^{3)}$ Early lymphocyte recovery during chemotherapy has been associated with a better prognosis. ${ }^{11-13,15-17)}$ In the present study, we observed that a higher pretreatment lymphocyte count was associated with favorable prognosis of pediatric osteosarcoma, while the day 14 lymphocyte count was not. Interestingly, the LMR14 was associated with better survival of pediatric patients with osteosarcoma.

There are some limitations in our study. First, this was a retrospec-
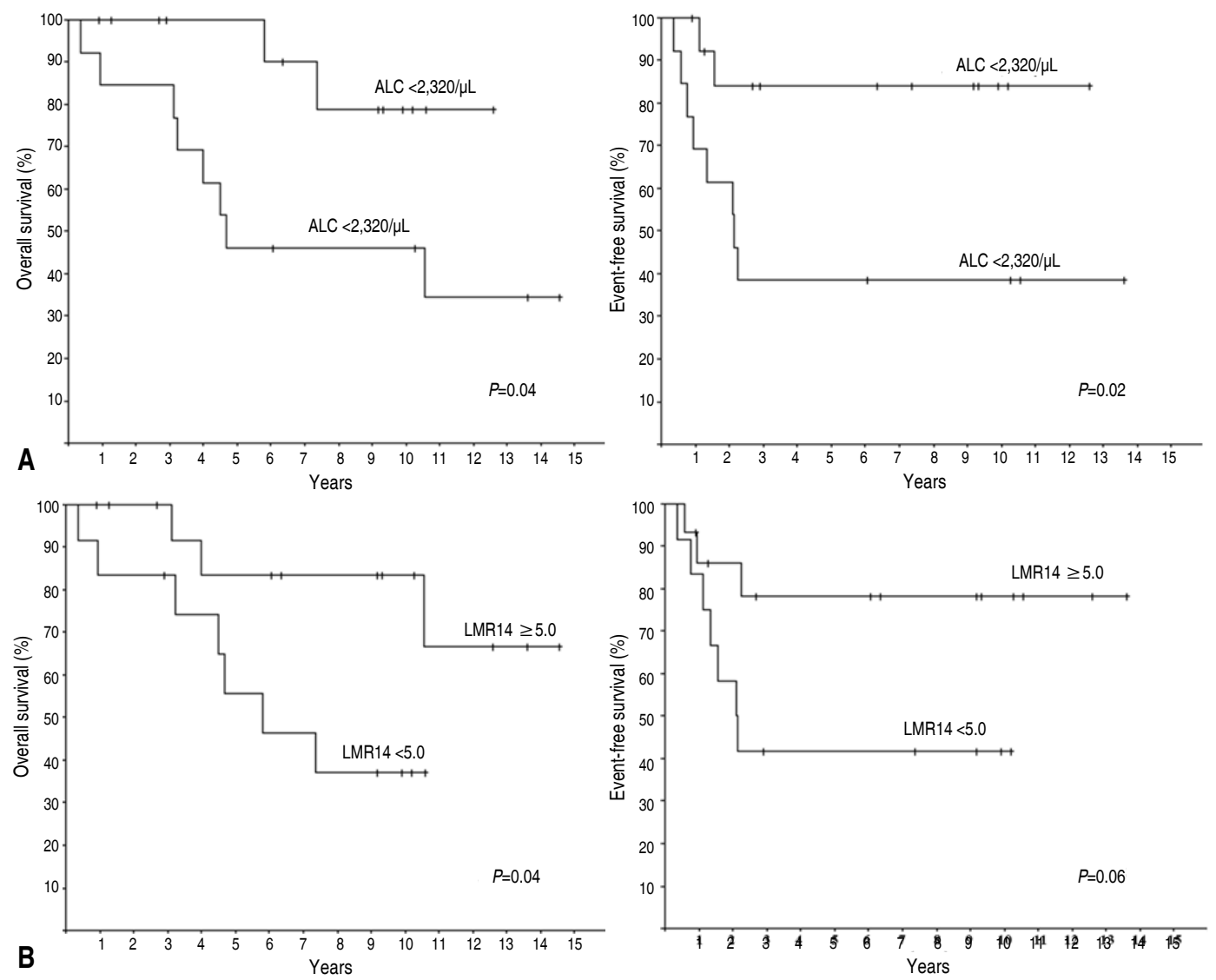

Fig. 1. (A) Patients with a higher pretreatment absolute lymphocyte count (ALC) had better overall survival (OS) and eventfree survival (EFS). (B) Patients with a higher lymphocyte-monocyte ratio on day 14 of chemotherapy (LMR14) had better $\mathrm{OS}$ and a tendency for better EFS. 
tive study involving a small number of patients and treatments were not homogeneous, with 7 cases receiving surgery before chemotherapy. However, the survival rates of the 7 patients were similar to those who received chemotherapy before surgery, and we assumed that treatment heterogeneity had little impact on our study. Second, we analyzed the leukocyte count of the peripheral blood as a surrogate for the patients' immune systems. Lymphocyte or monocyte infiltrates in the osteosarcoma tissue would more accurately reflect the anti-tumor immune response. However, this evaluation was not possible due to a limited amount of the biopsy samples; instead, we presumed that peripheral leukocyte count might correlate with lymphocyte or monocyte infiltrates in the osteosarcoma tissue.

It is unclear why osteosarcoma patients with a higher LMR had a better outcome. We surmised that LMR in peripheral blood may be surrogate of tumor-infiltrating immune cell populations and reflect a balance between immune effector cells (lymphocytes) and the tumor microenvironment (monocytes). Many studies demonstrated that lymphocyte counts in peripheral blood and the presence of tumor-infiltrating lymphocytes (TIL) are associated with favorable prognosis in patients with melanoma, lung, kidney, breast and ovarian cancer. ${ }^{19-21)}$ Meanwhile, it is suggested that lymphocyte counts in peripheral blood are prognostic due to an association with disease burden rather than TILs. ${ }^{22)}$ In contrast, monocytes or macrophages could promote tumor progression. ${ }^{23-26)}$ Increased numbers of monocytes in tumor tissues (tumor-associated macrophages, TAMs) were associated with the reduced survival of cancer patients. ${ }^{25,26)}$ TAMs are derived from monocytes in the peripheral blood and secrete cytokines, suppress the immune response, and promote angiogenesis. ${ }^{26)}$ It has been suggested that some monocytes in the peripheral blood may be myeloid-derived suppressor cells (MDSC). ${ }^{27}$ Elevated numbers of MDSCs in the peripheral blood were associated with shorter survival in patients with nonsmall cell lung cancer, colorectal, bladder, and thyroid cancers. ${ }^{27)}$ Recent studies have demonstrated that a high MDSC number are correlated with a poor response to ipilimumab or nivolumab. ${ }^{28,29)}$ We surmised that LMR in peripheral blood may be surrogate of tumor-infiltrating immune cell populations and reflect a balance between immune effector cells (lymphocytes) and the tumor microenvironment (monocytes). As the exact relationship between 2 compartments (peripheral blood and tumor microenvironment) is poorly understood, further studies are necessary.

While the prognostic significance of pretreatment LMR has been reported for several cancers, ${ }^{4-9,10,13)}$ little data exist about the postchemotherapy LMR. In patients with diffuse large B-cell lymphoma, a low peripheral blood ALC/AMC ratio during R-CHOP cycle predicted inferior outcome. ${ }^{30)}$ In patients with acute lymphoblastic leukemia, ${ }^{11,12)}$ non-Hodgkin lymphoma ${ }^{13)}$ Ewing sarcoma, ${ }^{17)}$ and osteosarcoma, ${ }^{15,16)}$ early lymphocyte recovery after chemotherapy is associated with a better outcome. Lymphopenia or late recovery during chemotherapy may be the result of preexisting immune dysfunction and/or T-lymphocyte inhibiting cytokines produced by the tumor cells. ${ }^{22)}$ We consider that a high LMR following chemotherapy suggests a dominant antitumor immune response of the lymphocytes.

In conclusion, a higher pretreatment lymphocyte count at diagnosis was associated with favorable prognosis of pediatric osteosarcoma, while the day 14 lymphocyte count was not. Furthermore, LMR14 after the first cisplatin-doxorubicin chemotherapy was associated with an improved outcome in pediatric patients with osteosarcoma. These indices may be used as prognostic indicators and potentially as biomarkers to predict the clinical response to immunotherapy in patients with osteosarcoma. As limited data exist about the prognostic significance of postchemotherapy LMR, further studies involving larger cohorts are necessary to validate our findings.

\section{Conflicts of interest}

No potential conflict of interest relevant to this article was reported.

\section{Acknowledgments}

This study was supported by a grant from the Korea Institute of Radiological and Medical Sciences (KIRAMS), funded by the Ministry of Science and ICT (MSIT), Republic of Korea (1711042677; 17110445548; 1711045553; 171104555/50534-2017).

\section{References}

1. Isakoff MS, Bielack SS, Meltzer P, Gorlick R. Osteosarcoma: current treatment and a collaborative pathway to success. J Clin Oncol 2015;33:3029-35.

2. Pakos EE, Nearchou AD, Grimer RJ, Koumoullis HD, Abudu A, Bramer JA, et al. Prognostic factors and outcomes for osteosarcoma: an international collaboration. Eur J Cancer 2009;45:2367-75.

3. Ray-Coquard I, Cropet C, Van Glabbeke M, Sebban C, Le Cesne A, Judson I, et al. Lymphopenia as a prognostic factor for overall survival in advanced carcinomas, sarcomas, and lymphomas. Cancer Res 2009;69:5383-91.

4. Nishijima TF, Muss HB, Shachar SS, Tamura K, Takamatsu Y. Prognostic value of lymphocyte-to-monocyte ratio in patients with solid tumors: a systematic review and meta-analysis. Cancer Treat Rev 2015;41:971-8.

5. Sun HL, Pan YQ, He BS, Nie ZL, Lin K, Peng HX, et al. Prognostic performance of lymphocyte-to-monocyte ratio in diffuse large B-cell lymphoma: an updated meta-analysis of eleven reports. Onco Targets Ther 2016;9:3017-23.

6. Vassilakopoulos TP, Dimopoulou MN, Angelopoulou MK, Petevi K, Pangalis GA, Moschogiannis M, et al. Prognostic implication of the 
absolute lymphocyte to absolute monocyte count ratio in patients with classical Hodgkin lymphoma treated with doxorubicin, bleomycin, vinblastine, and dacarbazine or equivalent regimens. Oncologist 2016;21:343-53.

7. Ni XJ, Zhang XL, Ou-Yang QW, Qian GW, Wang L, Chen S, et al. An elevated peripheral blood lymphocyte-to-monocyte ratio predicts favorable response and prognosis in locally advanced breast cancer following neoadjuvant chemotherapy. PLoS One 2014;9:e111886.

8. Wu Q, Hu T, Zheng E, Deng X, Wang Z. Prognostic role of the lymphocyte-to-monocyte ratio in colorectal cancer: an up-to-date metaanalysis. Medicine (Baltimore) 2017;96:e7051.

9. Li W, Ma G, Wu Q, Deng Y, Liu Y, Wang J. Prognostic value of lymphocyte-to-monocyte ratio among Asian lung cancer patients: a systematic review and meta-analysis. Oncotarget 2017;8:110606-13.

10. Li J, Jiang R, Liu WS, Liu Q, Xu M, Feng QS, et al. A large cohort study reveals the association of elevated peripheral blood lymphocyte-to-monocyte ratio with favorable prognosis in nasopharyngeal carcinoma. PLoS One 2013;8:e83069.

11. Rubnitz JE, Campbell P, Zhou Y, Sandlund JT, Jeha S, Ribeiro RC, et al. Prognostic impact of absolute lymphocyte counts at the end of remission induction in childhood acute lymphoblastic leukemia. Cancer 2013;119:2061-6.

12. Hirase S, Hasegawa D, Takahashi H, Moriwaki K, Saito A, Kozaki A, et al. Absolute lymphocyte count at the end of induction therapy is a prognostic factor in childhood acute lymphoblastic leukemia. Int $\mathrm{J}$ Hematol 2015;102:594-601.

13. Porrata LF, Inwards DJ, Ansell SM, Micallef IN, Johnston PB, Gastineau DA, et al. Early lymphocyte recovery predicts superior survival after autologous stem cell transplantation in non-Hodgkin lymphoma: a prospective study. Biol Blood Marrow Transplant 2008; 14:807-16.

14. Liu T, Fang XC, Ding Z, Sun ZG, Sun LM, Wang YL. Pre-operative lymphocyte-to-monocyte ratio as a predictor of overall survival in patients suffering from osteosarcoma. FEBS Open Bio 2015;5:682-7.

15. Moore C, Eslin D, Levy A, Roberson J, Giusti V, Sutphin R. Prognostic significance of early lymphocyte recovery in pediatric osteosarcoma. Pediatr Blood Cancer 2010;55:1096-102.

16. Lee L, Fei L, Pope J, Wagner LM. Early lymphocyte recovery and outcome in osteosarcoma. J Pediatr Hematol Oncol 2017;39:179-83.

17. DuBois SG, Elterman K, Grier HE. Early lymphocyte recovery in Ewing sarcoma. J Pediatr Hematol Oncol 2007;29:351-2.

18. Rosen G, Marcove RC, Huvos AG, Caparros BI, Lane JM, Nirenberg A, et al. Primary osteogenic sarcoma: eight-year experience with adjuvant chemotherapy. J Cancer Res Clin Oncol 1983;106 Suppl:55-67.
19. Tuthill RJ, Unger JM, Liu PY, Flaherty LE, Sondak VK; Southwest Oncology Group. Risk assessment in localized primary cutaneous melanoma: a Southwest Oncology Group study evaluating nine factors and a test of the Clark logistic regression prediction model. Am J Clin Pathol 2002;118:504-11.

20. Hadrup S, Donia M, Thor Straten P. Effector CD4 and CD8 T cells and their role in the tumor microenvironment. Cancer Microenviron 2013; 6:123-33.

21. Badalamenti G, Fanale D, Incorvaia L, Barraco N, Listi A, Maragliano R, et al. Role of tumor-infiltrating lymphocytes in patients with solid tumors: Can a drop dig a stone? Cell Immunol 2018 Jan 30 [Epub]. pii: S0008-8749(18)30014-5. https://doi.org/10.1016/j.cellimm.2018.01.013.

22. Milne K, Alexander C, Webb JR, Sun W, Dillon K, Kalloger SE, et al. Absolute lymphocyte count is associated with survival in ovarian cancer independent of tumor-infiltrating lymphocytes. J Transl Med 2012;10:33.

23. Bishara S, Griffin M, Cargill A, Bali A, Gore ME, Kaye SB, et al. Pretreatment white blood cell subtypes as prognostic indicators in ovarian cancer. Eur J Obstet Gynecol Reprod Biol 2008;138:71-5.

24. Schmidt H, Bastholt L, Geertsen P, Christensen IJ, Larsen S, Gehl J, et al. Elevated neutrophil and monocyte counts in peripheral blood are associated with poor survival in patients with metastatic melanoma: a prognostic model. Br J Cancer 2005;93:273-8.

25. Koh YW, Shin SJ, Park C, Yoon DH, Suh C, Huh J. Absolute monocyte count predicts overall survival in mantle cell lymphomas: correlation with tumour-associated macrophages. Hematol Oncol 2014;32:17886.

26. Chanmee T, Ontong P, Konno K, Itano N. Tumor-associated macrophages as major players in the tumor microenvironment. Cancers (Basel) 2014;6:1670-90.

27. Veglia F, Perego M, Gabrilovich D. Myeloid-derived suppressor cells coming of age. Nat Immunol 2018;19:108-19.

28. Sade-Feldman M, Kanterman J, Klieger Y, Ish-Shalom E, Olga M, Saragovi A, et al. Clinical significance of circulating CD33+ CD11b+ HLA-DR-myeloid cells in patients with stage IV melanoma treated with ipilimumab. Clin Cancer Res 2016;22:5661-72.

29. Tanizaki J, Haratani K, Hayashi H, Chiba Y, Nakamura Y, Yonesaka K, et al. Peripheral blood biomarkers associated with clinical outcome in non-small cell lung cancer patients treated with nivolumab. J Thorac Oncol 2018;13:97-105.

30. Porrata LF, Ristow KM, Habermann TM, Witzig TE, Colgan JP, Inwards DJ, et al. Peripheral blood absolute lymphocyte/monocyte ratio during rituximab, cyclophosphamide, doxorubicin, vincristine and prednisone treatment cycles predicts clinical outcomes in diffuse large B-cell lymphoma. Leuk Lymphoma 2014;55:2728-38. 